Article

\title{
Intercultural Learning Challenges Affecting International Students' Sustainable Learning in Malaysian Higher Education Institutions
}

\author{
Amr Abdullatif Yassin ${ }^{1, *}\left(\mathbb{D}\right.$, Norizan Abdul Razak ${ }^{1, *}$, Yousef A. M. Qasem ${ }^{2, *}$ (D) and \\ Murad Abdu Saeed Mohammed ${ }^{3}$ \\ 1 School of Language Studies and Linguistics, Faculty of Social Sciences and Humanities, \\ National University of Malaysia, Bangi, Kajang, Selangor 43600, Malaysia \\ 2 Faculty of Computer Science and Information Technology, University of Putra Malaysia, \\ Serdang 43400, Malaysia \\ 3 Department of English, Unaizah College of Sciences and Arts, Qassim University, \\ Unaizah 51911, Qassim, Saudi Arabia; muradsaeed16@yahoo.com \\ * Correspondence: amryassin84@gmail.com (A.A.Y.); norjef@ukm.edu.my (N.A.R.); \\ y.alsharaei@gmail.com (Y.A.M.Q.)
}

Received: 27 July 2020; Accepted: 7 September 2020; Published: 11 September 2020

check for updates

\begin{abstract}
The tendency for internationalization of higher education in many Higher Education Institutions (HEIs) around the world, including those of Malaysia, is increasing with the current wave of globalization; however, the main challenge of international HEIs is how to manage intercultural diversity and overcome intercultural learning challenges that affect international students' learning outcomes and learning sustainability. Hence, the aim of this study was to investigate intercultural learning challenges that affect international students' learning sustainability through a proposed measurement model. The data were collected from 273 international students in Malaysian HEIs through a survey and were analyzed using variance-based structural equation modeling (i.e., PLS-SEM). The results showed that intercultural challenges did not have a significant effect on students' learning sustainability. Nevertheless, language challenges, academic challenges, and research challenges were found to have a significant negative impact on the learning sustainability of international students. The study concluded that intercultural learning barriers are considered to be intercultural learning challenges, which have a negative effect on international students' learning sustainability even though international students might overcome such challenges with the passage of time. In addition, the study identified different factors pertaining to international students' learning sustainability, such as students' language and learning skills, Higher Education Institutions' educational systems, and lecturers. Based on the finding of the study, Higher Education Institutions need to create a clear framework that encompasses these factors to improve learning sustainability among international students.
\end{abstract}

Keywords: learning sustainability; Malaysian HEIs; international students; intercultural challenges; English language challenges; academic challenges; research challenges

\section{Introduction}

Nowadays, people live under the umbrella of globalization, which has erased the boundaries between cultures and made the aspects of each culture relatively well-known to other people [1,2]. Students are part and parcel of this experience, since they have their own choices to study in any other country. Intercultural learning increases benefits and awareness for international students $[3,4]$, and moving to any country has its influences on the lives of students due to cultural differences. Hence, 
intercultural adjustment of international students is an essential global topic because of its reflection on their personal behaviors and academic achievements $[5,6]$.

The relationship between intercultural adaptation and learning sustainability is essential, since intercultural barriers might hinder international students from gaining sustainable learning. International students move beyond borders to improve their knowledge and skills, and the chances for them to participate in sustainable development (SD) are high since they might be decision-makers, and they might participate in the education of future generations in their countries [7]. This perspective makes it important for higher education institutions (HEIs) to not only provide a high-quality learning experience for international students but also assist them to overcome intercultural learning challenges that might stand between them and their achievement of sustainable learning. This is also related to intercultural education, which requires adaptation of international students to the host culture as well as mastery of different elements such as language skills and academic gaining [8].

The number of international students is increasing in different countries every year $[9,10]$. In Malaysia, the number of international students in HEIs is escalating as recent statistics have demonstrated that there were 80,750 international students that joined Malaysian HEIs in 2009, and this number reached 111,939 in 2011 [11]. Internationalization of learning contributes $4 \%$ of Malaysian Gross National Income (GNI), and it was expected that this figure would be doubled in 2020 [12]. These statistics put more demand on education in Malaysian HEIs to go globally and compete through providing sustainable learning experiences to international students.

The main challenging issue is that international students are known for having different cultural and educational backgrounds, and different experiences; hence, managing diversity in higher education is not an easy task [13]. The increasing wave of globalization and internationalization of education might render the learning sustainability of international students as not only a current issue but also a constant emerging issue.

Moreover, international students experience different challenges, including general living adaptation, academic challenges, and adjusting to the new educational and cultural systems in the host country [6,14-16]. This makes studies on intercultural learning valuable for scholars and HEIs in mitigating intercultural learning barriers, fostering education, and improving students' sustainable learning $[17,18]$.

Previous literature has investigated education sustainability from different perspectives such as education, technology, employment, teachers, and curriculums [19-23]. However, there is a gap in the literature in the investigation of intercultural learning challenges that affect international students' sustainable learning. The current study attempts to bridge this gap by focusing on intercultural learning challenges, namely intercultural challenges, language challenges, academic challenges, and research challenges, which might hinder international students' learning sustainability in the Malaysian context. The items under every construct are linked not only to international students but also to HEIs in terms of education systems, lecturers, and facilities. This will give a clear overview for the interlink between students, lecturers, and HEIs to improve learning sustainability.

Previous literature has revealed different intercultural learning challenges, which are encountered by international students in different contexts. One of these challenges is communication with lecturers and local students [24-26]. Such intercultural communication challenges are due to students' English language proficiency. In addition, international students find it difficult to understand spoken English used inside the class, which might be attributed to students' limited vocabulary and speech pace of the lecturers [27-29]. Language barriers are not related to communication only because international students encounter similar challenges in writing and reading in English as well [30]. Such challenges have a negative effect on their adaptation to the new educational system of HEIs in the host country [6].

Sometimes, language proficiency tests might not help learners in their smooth and successful communication with native speakers. International students may study the English language in their home countries, but using it in real communicative situations might still be a barrier for them [31,32]. Long and Yan [33] pointed out that even though Chinese students travel to study in the USA after 
getting high scores in the TOEFL and GRE exams, they find it difficult to communicate with their lecturers and other students due to issues with intonation and pace of speech.

Other factors behind international students' language challenges are misunderstanding for the conventional cultural codes, idioms, and terms used in particular host settings $[26,34,35]$. This suggests that cultural differences create a gap between international students and their teachers, and hinders their assimilation to the host culture. For example, a student might be familiar with question-asking during the classes, yet he/she may not be able to do so in the class in some cultural contexts [36-38]. Besides, Mehdizadeh and Scott [39] argued that international students are challenged by how to successfully interpret non-verbal cultural codes during communication with others in the host culture [40-42]. This, therefore, affects their intercultural adaptation, and raises the question about the ability of the international students to gain sustainable learning in host HEIs.

Other challenges include those related to international students learning due to education systems, which differ from those in in their home countries. Hence, international students might not be able to perform well because of their failure or inability to meet the requirements of the new educational system in the host culture $[39,43]$. For instance, Li and Campbell [44] investigated the cultural adjustment of Asian learners in New Zealand, and the study revealed that international students face several challenges varying from their patterns of classroom interaction and lack of academic norms and conventions to inadequate support inside the classroom. These challenges negatively affect the process of learning among international students. Another study by bin Basri [16] in Malaysia revealed that the research-oriented educational system represents a challenging issue for many international students. However, this is seen as a benefit rather than a barrier because from students' perspectives, they can gain sustainable education related to knowledge and academic research skills.

Moreover, other factors that can affect international students' learning could unexpected academic achievements that are valued by students. However, an inability to achieve such academic goals may create anxiety and sense of lacking self-confidence, and may also affect the funding which the learners receive from their families. Further, learners might lose their incentive towards study and motivation to study hard and spend more time in studying when they do not achieve their academic goals [40,45-48].

In addition, the educational quality of host institutions can be inferred from the learning experiences of international students and their satisfaction with their knowledge gaining [49,50]. Attention, therefore, should be given to the quality of education in addition to assistance in order to enable international students to overcome intercultural learning barriers. This shows the role of intercultural competency in HEIs in order to provide sustainable learning to international students [8]. According to Lu and Mundorf [51], Education for Sustainable Development (ESD) might not be easy to achieve, as their findings showed that Chinese students in the US lack building sustainable skills due to their low adaptation to learning discussions in the classroom, but they could learn how to get such sustainable skills through informal communication and interactions with other people in the host country.

In addition, the term "learning sustainability", which is discussed under Sustainable Development (SD), is often understood within the context of solving environmental issues. However, education is a key element in this context, and it is generally referred to as Education for Sustainable Development (ESD). Moreover, education sustainability is one of the goals of the United Nations (UN) to be achieved during the period 2016-2030, and the goal focuses on providing quality and life-long learning to all people worldwide (United Nations, 2015). According to Samuelsson and Park [52], the UN General Secretary Ban proposed the initiative called "Education for all" in 2012 to shift the process of education towards learning, which puts more emphasis on learners. The shift of focus in terms of education sustainability to learning highlights the significant role of HEIs in providing sustainable learning to all students, including international students. Scholars have investigated education sustainability in HEIs from different perspectives such as focusing on educational systems, employment, curriculums, teachers, and technology [19-21,23]. Nevertheless, learners' achievements, 
knowledge, and skills are still discussed under the term education sustainability [53]. Hence, the term learning sustainability in this study is used to refer to students' abilities to obtain sustainable learning and improve their knowledge, and academic and research skills, all of which are required by their future occupations $[7,53,54]$.

Moreover, the globalization wave has directed many countries and HEIs to focus on the internationalization of education. This trend shows that intercultural education or learning aims to attain sustainable development, including the intercultural competency of students [8]. Intercultural education goes beyond the general description of education systems to promote the individual learning experience of students, which is a challenge for HEIs to include these goals in their strategies and goals [8,18,55].

The focus on international students through providing intercultural education has become the goal of many prominent HEIs in different parts of the world. The eventual aim is to provide international students with the necessary skills in assimilating and adapting to the host culture and attaining the required knowledge and skills that enable them to actively participate in the sustainable development of their societies. According to Hatipoglu and Ertuna [55], ESD requires focusing on education quality and providing practical training to ensure sustainable development among learners. That is, ESD required a systemic or connected view of sustainability which might link different HEIs "glocally" in order to transform the educational experience of students towards sustainable outcomes [56]. In the Malaysian context, major universities seem aware of the significance of education sustainability, and, therefore, they have incorporated such goals in their strategies, visions, and missions [57].

To summarize, international students encounter different intercultural learning barriers such as intercultural adaptation and language, academic, and research barriers. Providing education for sustainable development is still a major concern for HEIs worldwide. Moreover, the promotion of learning among international students requires improving their learning experience and skills; however, such intercultural learning barriers might negatively affect this endeavor. Therefore, the current study focuses on intercultural learning barriers among international students in Malaysian HEIs as factors that might have a negative impact on learning sustainability, and it aims to answer the following questions:

a. What are the intercultural adaptation challenges for international students in Malaysian HEIs?

b. What are the intercultural learning challenges (academic, language and research) for international students in Malaysian HEIs?

A research hypothesis is a "logically conjectured relationship between two or more variables expressed in the form of a testable statement" [58]. Based on the research questions above, the study has developed four research hypotheses, which are presented below.

\section{a. Intercultural Challenges}

The term "intercultural challenges" is related to adaptation barriers, which international students encounter when they move to study in a new culture. Intercultural challenges have been investigated by different studies, which showed that such challenges have a negative effect on students' learning and academic achievements [6,59]. The negative effect of intercultural challenges might have a negative effect on international students' learning outcomes, which is related to gaining sustainable learning $[7,53,54]$. Therefore, it is hypothesized that:

Hypothesis 1 (H1). Intercultural challenges affect the learning sustainability of international students.

\section{b. Language Challenges}

English language proficiency is a main requirement of international HEIs, and international students therefore cannot join these HEIs unless they have mastered the English language. Previous literature showed that international students gain English proficiency before traveling to study abroad, but they face language barriers, which has a negative influence on their academic 
achievement $[6,29,33,51]$. Hence, this might affect their opportunity to engage in sustainable learning, which led to the second hypothesis of the study that:

Hypothesis 2 (H2). English language challenges affect the learning sustainability of international students.

\section{c. Academic Challenges}

Academic challenges are related to learning processes and understanding lecturers and the educational systems of the university. Previous literature shows that international students encounter challenges in the host university because learning process and requirements are different from their previous experience $[6,60,61]$, and such academic challenges might have a negative influence on gaining sustainable learning [62]. Accordingly, it was postulated that:

Hypothesis 3 (H3). Academic challenges affect the learning sustainability of international students.

\section{d. Research Challenges}

Improving research skills is essential for all students, including international students, since they need them for their future employment. However, international students might encounter challenges in enhancing their research skills [16], which would have a negative influence on learning sustainability $[16,63]$. Thus, it is postulated that:

Hypothesis 4 (H4). Research challenges affect the learning sustainability of international students.

Based on the above research hypotheses, the current study aimed to (a) investigate the effect of intercultural challenges on learning sustainability among international students in in Malaysian HEIs; (b) investigate the effect of language challenges on learning sustainability among international students in in Malaysian HEIs; (c) investigate the effect of academic challenges on learning sustainability among international students in in Malaysian HEIs; and (d) investigate the effect of research challenges on learning sustainability among international students in Malaysian HEIs.

\section{Material and Methods}

\subsection{Research Design}

The study adopted a quantitative cross-sectional survey strategy which investigates the relationship between the independent variable and the independent variables. This quantitative research has been extensively used in social studies due to its positivist/post-positivist paradigm that allows researchers to get the participants' responses or determine their attitudes through quantitative data [64]. Hence, the data of the study were collected through a survey, which was designed and distributed to students, who are studying different majors in different universities in Malaysia. This design was suitable for the study to investigate the intercultural learning challenges that affect sustainable learning among international students in Malaysian HEIs. Thus, the quantitative data helped to understand the intercultural learning challenges of international students, who are known for having different cultural, lingual, and educational backgrounds, and this helped to get the general picture related to the research objectives and questions of the current study [65].

\subsection{Sample}

Designing a targeted sample is evident because selecting a representative segment of the population provides conclusions that are generalizable to the overall targeted population [58]. In the present study, the purposive sampling method was chosen to collect the data. In order to determine the sample size 
required for the present study, the sample was selected by observing past literature rules of thumb associated within the SEM and PLS modeling techniques. Krejcie and Morgan [66] came up with a table for determining sample size for a given population for easy reference. For 220 of N population, a sample size of 140 is required $[58,66]$. On the other hand, four rules proposed by [67] for determining and establishing a sample size are: (1) sample sizes of $n>30$ and $n<500$ are appropriate for most research, (2) a minimum sample size of 30 is sufficient for cases that require splitting samples into sub-samples such as males or females, junior employees or senior employees, (3) in multivariate analysis, the sample size is required to be at least 10 times greater than the number of the variables in the model. For simple experimental research with full control over respondents' behavior, a small sample size comprising 10 to 20 persons is sufficient.

The calculation of the needed number of respondents was carried out based on the requirements of PLS-SEM. Barclay and Higgins [68] proposed that the thumb role for sampling is 10 multiplied by the maximum number of formative indicators. O'Rourke and Hatcher [69] posited that the sample size needs to be five times higher than the number of variables, and they also stated that the sample size needs to be at least 100 regardless of the number of the items of the study. According to the first rule, this study needed 40 respondents as the minimum sample size for the analysis of the proposed model using the SEM approach. Nevertheless, Hair Jr and Hult [70] believes that the number of sample size has a rough guideline and PLS-SEM, as a statistical tool, requires a sample size dependent on the side of the model with the maximum number of predictors. Likewise, this study applied $\mathrm{G}^{*}$ power software to test the sufficiency of the sample size [71], to determine the smallest required sample size. According to the setting proposed by Vidaver-Cohen [72] ( $\mathrm{f} 2=0.15$ for effect size, $\alpha=0.05$ for error type one, and $\beta=0.20$ for error type two) and for four independent constructs or predictors, the suggested sample size was 129 (see Figure 1).

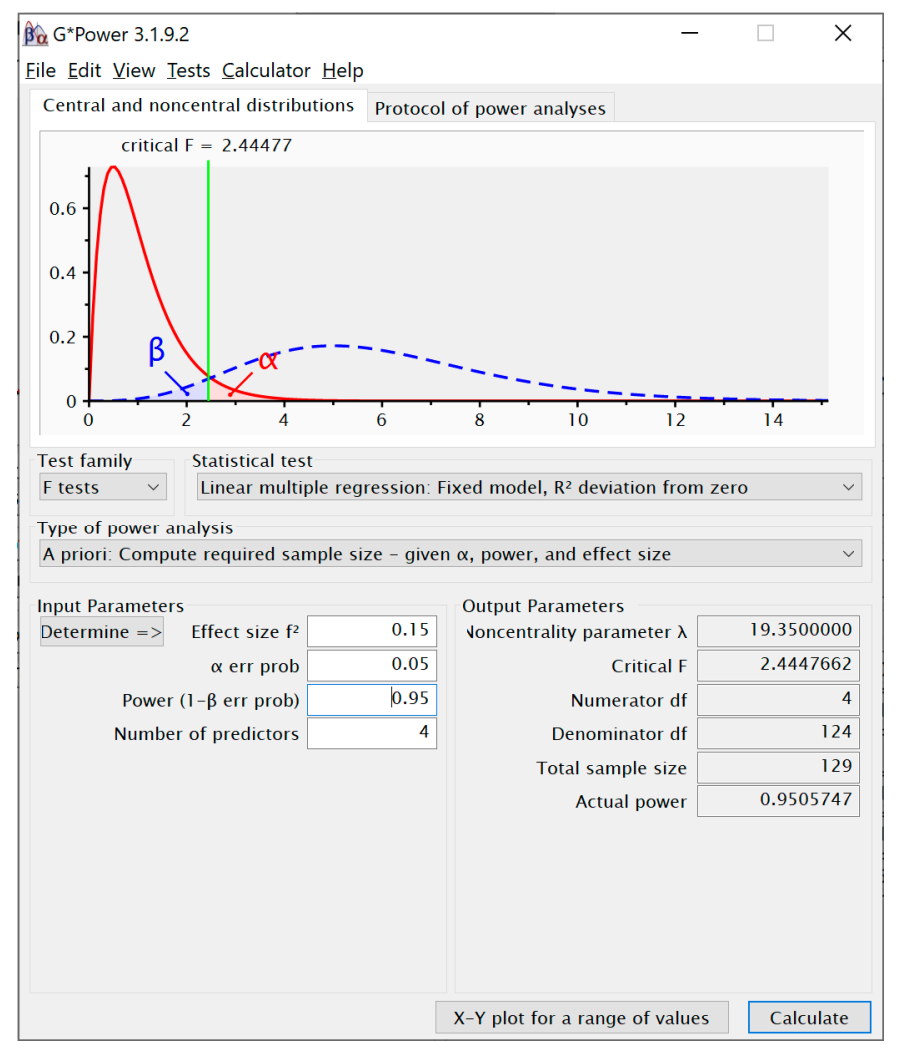

Figure 1. $G^{*}$ power Interface and Settings.

Following the above rule and the statistical analysis plan selected for this research, the total sample collected for the main study $(n=140)$ was large enough to test the parameters of this model. The number 
of students who responded to the survey was 273. All the participants were international students studying different majors in different public and private Malaysian HEIs, including UUM, UPM, UKM, UM, UMP, Limkokwing, USM, UTHM, UTM, IIUM, UiTM, UnimAPP, USIM, UNITEN, MSU, IUMW, UMT, Nilai University, Segi University, and City University. In terms of gender, the number of females was $101(37 \%)$, while the number of males was $172(63 \%)$. Also, the number of undergraduate students was $20(7 \%)$ students, and the number of postgraduate students was $253(93 \%)$ students. The survey was sent online, and 273 international students gave their responses. After data screening for missing values, skewness, kurtosis, validity, reliability, factor loading, and outliers using SPSS version 22, all of the 273 responses were included in the study.

\subsection{Instrument and Data-Collection}

The data were collected through a survey designed for the study. The survey was developed after two steps. The first step included reviewing previous literature, and the second step included conducting short interviews with seven international students to explore the possibility of adding new constructs or items to the survey. After the design of the survey, it was validated by three experts to ensure that every item was related to the factor under investigation. Also, the survey was piloted to 40 students to investigate if there are any complications in the study, and to test its reliability. Pilot study analysis through Cronbach's Alpha was 0.77 , which shows that the survey has a good internal consistency.

The survey was composed of six sections. The first section was used to investigate the background information of the students, namely level of study, gender, nationality, and university. The second section was the dependent variable (DV), composed of 5 items. The third, fourth, fifth, and sixth sections were the independent variables (IVs). That is, the third section was made of 3 items used to investigate the intercultural challenges (ICC). The fourth section was made of nine items to investigate the language challenges (LC). The fifth section was made of 3 items to investigate research challenges $(\mathrm{RC})$, and the sixth section was made of 4 items to investigate the academic challenges (AC). The survey was designed with a five-point Likert-scale, ranging from one point for strongly disagree to five points to strongly agree for all the items of all the study constructs. Table 1 shows the intercultural learning challenges discussed in previous literature, which are faced by international students, and which might hinder their gaining for sustainable learning. 
Table 1. Constructs of the study.

\begin{tabular}{|c|c|c|c|}
\hline Construct & IV/DV & Items & Sources \\
\hline Learning Sustainability (LS) & DV & $\begin{array}{l}\text { My English language is good now. } \\
\text { Research facilities available in my university helped me to improve my research skills. } \\
\text { My Professors helped me to improve my research skills. } \\
\text { Lectures are helpful to solve my academic difficulties. } \\
\text { I could overcome any academic challenges with the passage of time. } \\
\text { I had serious cultural difficulties when I arrived in Malaysia. }\end{array}$ & {$[6,7,53,54,59]$} \\
\hline Intercultural Challenges (ICC) & IV & $\begin{array}{l}\text { It is difficult to adapt to the Malaysian culture. } \\
\text { At the beginning when I came to Malaysia, I wanted to reserve/keep my culture. } \\
\text { My English language was weak when I arrived in Malaysia. } \\
\text { It was difficult for me to understand the accent of lecturers at the beginning of my } \\
\text { study in Malaysia. }\end{array}$ & {$[6,29,51,73]$} \\
\hline Language Challenges (LC) & IV & $\begin{array}{l}\text { The lecturers speak so fast that I could not understand them at the beginning of my } \\
\text { study in Malaysia. } \\
\text { The lecturers use abbreviations which I do not know. } \\
\text { I had a limited vocabulary in English language at the beginning of my study. } \\
\text { I could not express myself well in English when I came to study in Malaysia. } \\
\text { My writing in English was weak when I started my study in Malaysia. } \\
\text { My grammar background in English was limited when I started my study in Malaysia. } \\
\text { My reading skills in English were not good when I started my study in Malaysia. } \\
\text { My research background was weak when I started my study in Malaysia. }\end{array}$ & {$[6,29,51,73]$} \\
\hline Research Challenges (RC) & IV & $\begin{array}{l}\text { My research skills were weak when I started my study in Malaysia. } \\
\text { I faced challenges in writing research/projects required from me at the beginning of } \\
\text { my study in Malaysia. } \\
\text { The academic system is different from that of my home country. }\end{array}$ & {$[16,63]$} \\
\hline Academic Challenges (AC) & IV & $\begin{array}{l}\text { I faced academic difficulties at the beginning of my study in Malaysia. } \\
\text { Academic difficulties affected my achievement when I started my study in Malaysia. } \\
\text { The methodology of teaching in Malaysia is different from } \\
\text { that of my home country. }\end{array}$ & {$[6,60-62]$} \\
\hline
\end{tabular}

LS (Learning sustainability; ICC (Intercultural challenges); LC (Language challenges); RC (Research challenges); AC (Academic challenges). 


\subsection{Data Analysis}

The data were analyzed using the Smart PLS package, and the reporting of the PLS estimates was based on the recommendations of Hair and Ringle [74] as well as the 2-step approach by Chin [75]. Both the measurement model and the path model were analyzed using 273 cases and 5000 samples [74]. There were no missing values in the data, which did not require any replacement measurement. In terms of SPSS, it was used for data screening (removing outliers and ensuring the distribution normality of the data), while Harman's single factor was also used to test sample bias.

\subsection{Ethical Considerations}

All the participants were informed in the self-administered online survey that their participation is voluntarily, and their responses will be confidential and used for research purposes only, while keeping their identity anonymous. The survey was sent online, and a number of 273 international students gave their consent to participate in the study.

\section{Results}

\subsection{Measurement Model}

The current study adopted the reflective measurement model, which has two types of validity assessments, namely convergent validity and discriminant validity.

Convergent validity is the degree to which the construct's indicators converge or share a high proportion of common variance [76]. In addition, Hair Jr and Hult [70] suggested using factor loadings and AVE to assess convergent validity. The results of this assessment are shown in Table 2. Also, Figure 2 illustrates the measurement model, in which all the constructs are reflective.

Table 2. Reliability and convergent validity.

\begin{tabular}{ccccc}
\hline Construct & Items & Loadings & Composite Reliability & Average Variance Extracted (AVE) \\
\hline DV & DV1 & 0.763 & 0.836 & 0.506 \\
& DV2 & 0.704 & & \\
& DV3 & 0.610 & & \\
& DV4 & 0.728 & & 0.619 \\
AC & DV5 & 0.740 & 0.867 & \\
& AC1 & 0.812 & & 0.549 \\
& AC2 & 0.815 & & \\
& AC3 & 0.726 & 0.782 & \\
ICC & AC4 & 0.792 & & \\
& ICC1 & 0.737 & & \\
& ICC2 & 0.607 & & \\
LC & ICC3 & 0.857 & & \\
& LC1 & 0.733 & & \\
& LC2 & 0.631 & & \\
& LC3 & 0.699 & & \\
& LC4 & 0.421 & & \\
& LC5 & 0.849 & & \\
& LC6 & 0.791 & & \\
RC & LC7 & 0.831 & & \\
& LC8 & 0.793 & & \\
& LC9 & 0.827 & & \\
& RC1 & 0.885 & & \\
& RC2 & 0.913 & 0.918 & \\
\hline
\end{tabular}

LS (Learning sustainability; ICC (Intercultural challenges); LC (Language challenges); RC (Research challenges); AC (Academic challenges). 


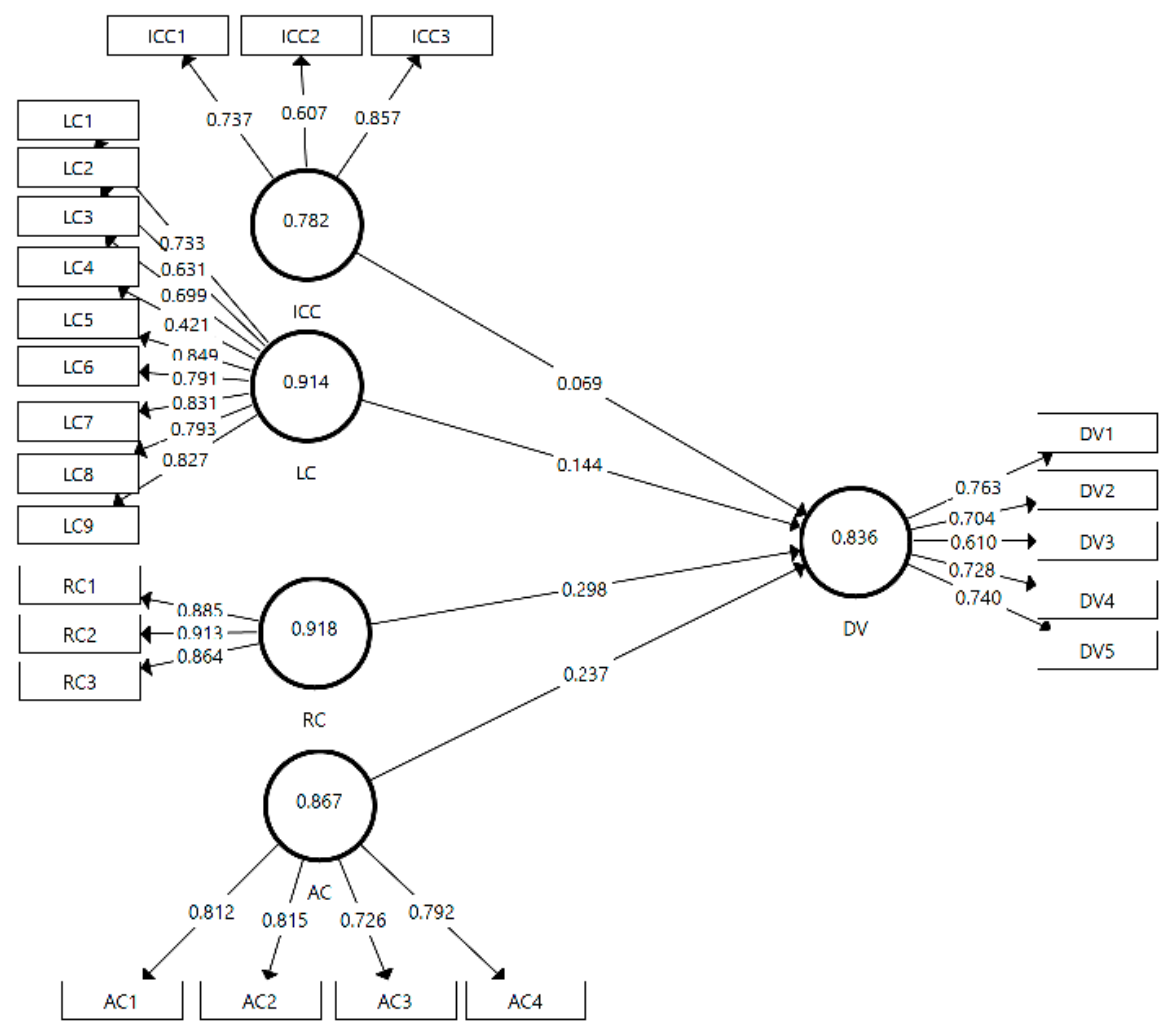

Figure 2. The Measurement Model.

The indicator loadings, Composite Reliability (CR), and Average Variance Extracted (AVE) of the reflective constructs are shown in Table 3. The recommended value to retain constructs was 0.708 [70]. Accordingly, the items of DV3, ICC2, LC2, LC3, and LC4 were adequate to complement with the threshold value of AVE and CR [70,77]. That is, all the five constructs met the threshold values/minimum cut-off values for CR and AVE, since all CRs were greater than 0.7 and all AVEs were greater than $0.5[70,78]$. It was concluded that the constructs meet reliability and convergent validity requirements at this stage.

Table 3. Discriminant Validity using the Fornell and Lacker Criterion.

\begin{tabular}{cccccc}
\hline & AC & DV & ICC & LC & RC \\
\hline AC & $\mathbf{0 . 7 8 7}$ & & & & \\
DV & 0.472 & $\mathbf{0 . 7 1 1}$ & & & \\
ICC & 0.286 & 0.225 & $\mathbf{0 . 7 4 1}$ & & \\
LC & 0.479 & 0.408 & 0.259 & $\mathbf{0 . 7 4 2}$ & \\
RC & 0.49 & 0.49 & 0.17 & 0.446 & $\mathbf{0 . 8 8 8}$ \\
\hline
\end{tabular}

Note: Diagonal represent the square root of the AVE while the off diagonals represent the correlations. DV (Dependent Variable; ICC (Intercultural challenges); LC (Language challenges); RC (Research challenges); AC (Academic challenges).

Accordingly, the discriminant validity of the model was assessed to ensure that all the indicators load more strongly on their own constructs than on other constructs in the model, and the shared average variance between the construct and its measures should be greater than the shared variance between each construct and other constructs [79]. Table 3 indicates that all constructs exhibited satisfactory discriminant validity [79], where the square root of AVE (diagonal) is larger than the correlations (off-diagonal) for all reflective constructs.

Table 4 shows discriminant analysis results by comparing the cross loadings between the different constructs of the study. The paper used cross loadings to assess discriminant validity, meaning each 
indicator should load high on its own construct but low on other constructs, and this was achieved in the current study, as shown in Table 4. Therefore, discriminant validity was achieved in this study since the constructs are distinctly different from each other.

Table 4. Cross-Loadings.

\begin{tabular}{cccccc}
\hline & AC & DV & ICC & LC & RC \\
\hline AC1 & $\mathbf{0 . 8 1 2}$ & 0.419 & 0.260 & 0.306 & 0.434 \\
AC2 & $\mathbf{0 . 8 1 5}$ & 0.300 & 0.219 & 0.441 & 0.424 \\
AC3 & $\mathbf{0 . 7 2 6}$ & 0.287 & 0.243 & 0.459 & 0.373 \\
AC4 & $\mathbf{0 . 7 9 2}$ & 0.434 & 0.185 & 0.351 & 0.325 \\
DV1 & 0.346 & $\mathbf{0 . 7 6 3}$ & 0.203 & 0.481 & 0.339 \\
DV2 & 0.291 & $\mathbf{0 . 7 0 4}$ & 0.187 & 0.173 & 0.325 \\
DV3 & 0.106 & $\mathbf{0 . 6 1 0}$ & 0.096 & 0.191 & 0.318 \\
DV4 & 0.402 & $\mathbf{0 . 7 2 8}$ & 0.235 & 0.196 & 0.382 \\
DV5 & 0.441 & $\mathbf{0 . 7 4 0}$ & 0.068 & 0.337 & 0.378 \\
ICC1 & 0.365 & 0.144 & $\mathbf{0 . 7 3 7}$ & 0.325 & 0.187 \\
ICC2 & 0.233 & 0.059 & $\mathbf{0 . 6 0 7}$ & 0.257 & 0.035 \\
ICC3 & 0.131 & 0.226 & $\mathbf{0 . 8 5 7}$ & 0.110 & 0.125 \\
LC1 & 0.306 & 0.305 & 0.100 & $\mathbf{0 . 7 3 3}$ & 0.255 \\
LC2 & 0.439 & 0.221 & 0.269 & $\mathbf{0 . 6 3 1}$ & 0.328 \\
LC3 & 0.440 & 0.265 & 0.260 & $\mathbf{0 . 6 9 9}$ & 0.338 \\
LC4 & 0.461 & 0.263 & 0.249 & $\mathbf{0 . 4 2 1}$ & 0.402 \\
LC5 & 0.315 & 0.367 & 0.188 & $\mathbf{0 . 8 4 9}$ & 0.305 \\
LC6 & 0.300 & 0.252 & 0.179 & $\mathbf{0 . 7 9 1}$ & 0.352 \\
LC7 & 0.396 & 0.351 & 0.190 & $\mathbf{0 . 8 3 1}$ & 0.344 \\
LC8 & 0.274 & 0.321 & 0.137 & $\mathbf{0 . 7 9 3}$ & 0.304 \\
LC9 & 0.323 & 0.320 & 0.197 & $\mathbf{0 . 8 2 7}$ & 0.370 \\
RC1 & 0.342 & 0.394 & 0.175 & 0.327 & $\mathbf{0 . 8 8 5}$ \\
RC2 & 0.457 & 0.426 & 0.144 & 0.382 & $\mathbf{0 . 9 1 3}$ \\
RC3 & 0.491 & 0.475 & 0.138 & 0.464 & $\mathbf{0 . 8 6 4}$ \\
\hline
\end{tabular}

DV (Dependent Variable; ICC (Intercultural challenges); LC (Language challenges); RC (Research challenges); AC (Academic challenges).

One of the most common method bias (CMB) tests of issues is Harman's single factor test [80]. In this study, Harman's single factor test was used with the statistical analysis software SPSS, 26.0 version. The analysis showed that a single factor was $28.8 \%$ of the total variance, and this value is far below the recommended $50 \%$. Hence, the analysis revealed no significant common method bias in the data set.

\subsection{Srtuctural Model}

It was necessary to carry out the structural model, since it is the second step of evaluating the proposed model of the study. Assessing the structural model requires different criteria [70]. Hence, the assessment was carried out using the PLS algorithm procedure, along with re-sampling techniques (bootstrapping).

The study used path coefficients from PLS with $p$-values and t-statistics (bootstrapping results) to test the hypotheses of the study in Table 5. Hence, the impact of the independent variables on learning sustainability was achieved by using the PLS-SEM approach. Table 5 shows the results' summary of the hypotheses examination. Accordingly, the values for " $t=3.091$ " and " $p<0.001$ ", " $t=2.326$ " and " $p<0.01$ ", and " $t=1.645$ " and " $p<0.05$ " were accepted for the t-value at different levels of significance, which is important in order to accept the study hypothesis through the structural model. The validation and rejection of the study hypothesis depends on the results of the path assessment $(\beta$, $t$-value, and $p$-value), which was also used to establish the impact of the association of the dependent and independent variables. In terms of the results of path coefficients and the significance level of the relationships in the structural model, they are shown in Table 5 and Figure 3 below. 
Table 5. Results of hypotheses testing.

\begin{tabular}{ccccccc}
\hline Hypothesis & Description & PathCoefficients $(\boldsymbol{\beta})$ & $\boldsymbol{t}$-Value & $\boldsymbol{p}$ Values & Significance Level & Results \\
\hline H1 & AC - > DV & 0.237 & 3.374 & 0.000 & $* *$ & Supported \\
H2 & ICC - DV & 0.069 & 1.053 & 0.146 & NS & Rejected \\
H3 & LC -> DV & 0.144 & 2.190 & 0.014 & $*$ & Supported \\
H4 & RC -> DV & 0.298 & 4.494 & 0.000 & $* *$ & Supported \\
\hline
\end{tabular}

Note: NS $=$ Not significant. ${ }^{*}$ Significance level $=\% 5\left({ }^{*} p<0.05\right) .{ }^{* *}$ Significance level $=\% 1\left({ }^{* *} p<0.01\right)$.

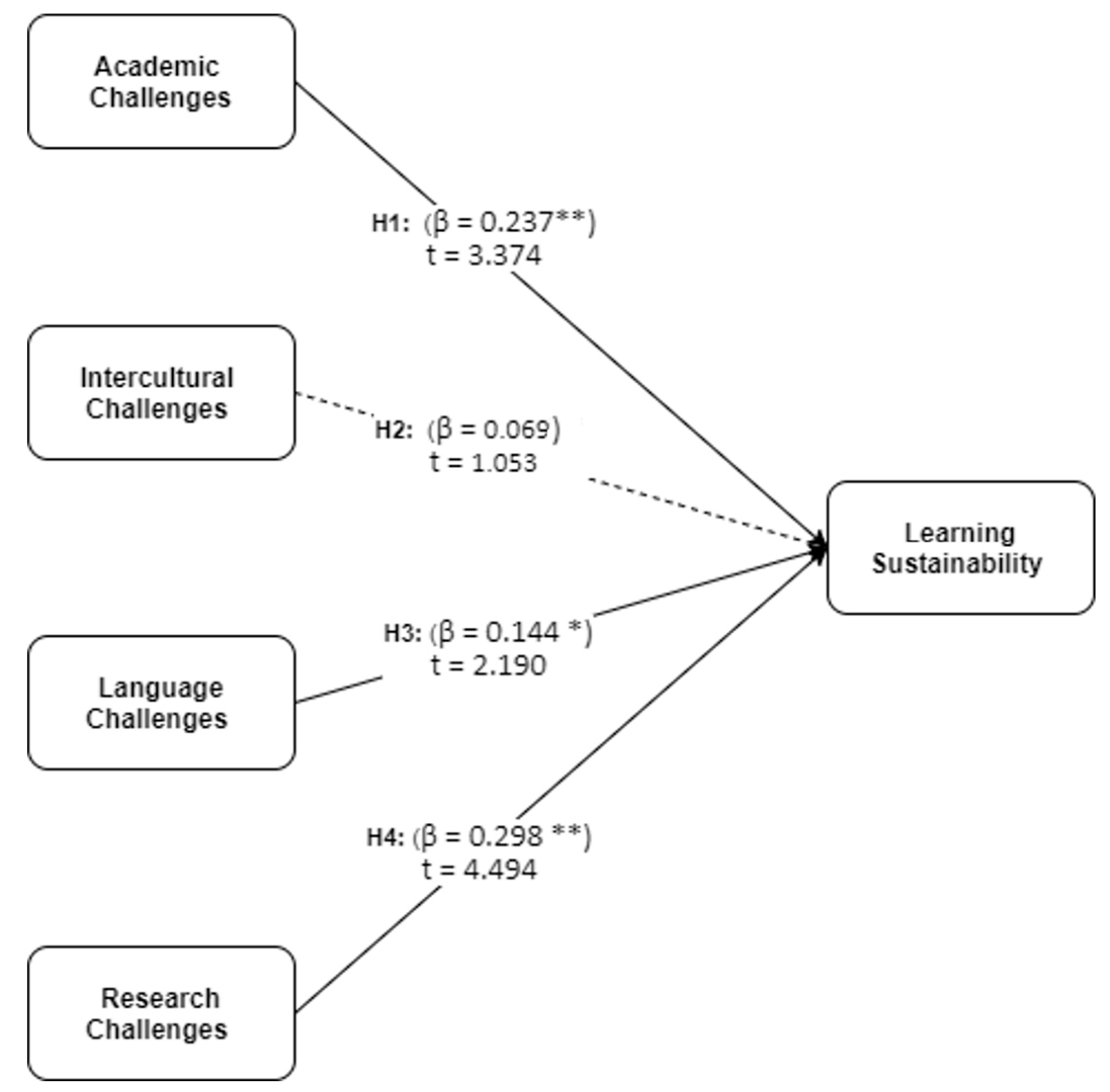

Figure 3. Results of the structural model. ${ }^{*}$ Significance level $=\% 5\left({ }^{*} p<0.05\right) .{ }^{* *}$ Significance level $=\% 1$ $(* * p<0.01)$.

The proposed hypotheses of the current study were confirmed according to the results, in which $p<0.01$ for $\mathrm{H} 1$ and $\mathrm{H} 4$, and $p<0.05$ regarding H3. Nevertheless, the results did not support $\mathrm{H} 2$ since it did not achieve the threshold $p$-value. In terms of bootstrapping, it was used with 5000 subsamples (a two-tailed, 0.05 significance level) as recommended by Hair Jr and Hult [70], and the aim was to obtain the standard error and t-statistics for the whole sample as well as the two sub-samples. Table 5 shows the results of the structural model assessment, which shows that three of the four main paths were significant from the overall sample. Besides, Table 5 illustrates that the path relationship between academic challenges and learning sustainability was significant $(\beta=0.237, p=0.000)$. Also, the effect of language challenges on learning sustainability was significant ( $\beta=0.144, p=0.014$ ). The relationship between research challenges and learning sustainability was significant as well $(\beta=0.298, p=0.000)$. In contrast, the relationship between intercultural challenges and learning sustainability was not significant $(\beta=0.069, p=0.146)$. 


\section{Discussion and Conclusions}

The aim of this paper was to investigate the effect of intercultural learning challenges on the learning sustainability of international students in Malaysian HEIs. The findings revealed that English language challenges have a negative effect on learning sustainability among international students. The role of English language in HEIs is essential, since it is the language of teaching. The survey showed that international students face challenges in the four language skills at the beginning of their academic study, taking into consideration that success depends mainly on students' ability to read materials, and write the assignments and the answers in exams using the English language. Also, international students need to communicate with their lecturers and classmates, especially in debates and workshops. Language challenges affect international students' sustainable learning because they limit students' acquisition for knowledge and improvement for learning skills [51,73]. The findings of this study in terms of English language challenges are in line with previous studies $[6,15,28,30,73,81]$, since language barriers may inhibit the ability of international students to take an active learning role inside the classroom. Even through the findings of the survey showed that international students face language challenges upon their arrival to study in Malaysia and could overcome language challenges with the passage of time, this does not eliminate the negative effect of language challenges on gaining sustainable learning among international students, especially since weak English language skills do not help them to improve their knowledge and skills, which they need for their future careers [53].

In terms of research in HEIs, the findings of the current study showed that research challenges have a negative impact on learning sustainability among international students. Discussing research in a general context, it is one of the main skills to be mastered at the university level, and it is more important for postgraduate students. The tendency of many HEIs to exploit research has become a strategy rather than a requirement because the success of any university can be measured through research outcomes, which is one of the key indicators for HEIs rankings and one of their main challenges $[8,18,55]$. Moreover, many HEIs offer different programs for students with a research mode only, which increases the importance of research skills among international students to acquire sustainable learning. International students might eventually need to carry out research projects when they go back to their home countries. Hence, research skills are not only an indicator for academic achievements and success at HEIs, but are also an essential skill for sustainable learning $[7,54,82]$. Therefore, research skills are one of the indicators for the outcomes of the students, which is a competency indicator for gaining sustainable learning [63,82].

In terms of academic challenges, the current study showed that this construct has a negative effect on students' learning sustainability, which supports the findings of previous studies $[6,40]$. That is, international students usually move to study in countries that offer a better education than that available in their homeland. The educational system in Malaysia is advancing year by year, and this can be easily noticed in the jump of Malaysian HEIs in the international Quacquarelli Symonds (QS) ranking. International students might encounter a new educational system that differs from their previous experience, which negatively affects their academic achievement. Nevertheless, there are other important aspects to improve sustainable learning among international students including teaching methodologies, use of technology in the process of teaching and learning, knowledge, and writing projects and assignments during the whole academic year $[5,6,59,83,84]$. Academic challenges might also have a negative impact on international students' sustainable learning if international students do not have the skills to overcome academic barriers [85]. The participants in the current study showed that the educational system in Malaysian HEIs is better in comparison to the teaching process and the academic requirements in their countries, and the admiration for the academic system in Malaysian HEIs is a reflection of the success of higher education in Malaysia $[49,86]$. Further, the participants showed that they could overcome academic challenges in the host country with the passage of time, indicating that overcoming academic challenges by international students is important for improving their learning outcomes, which is one of the essential factors to improve international students' sustainable learning. 
Besides, the findings of this study showed that intercultural challenges did not have a significant influence on learning sustainability, which is contrary to the findings of different previous studies [6,14-16]. Hence, the easier adaptation to the intercultural education in Malaysian HEIs may be attributed to different elements such as multiculturalism, HEIs policies and strategies, teachers' support for students, students' motivation to learn, and the effective learning process, showing that there are different interlaced educational and cultural factors that lead to the improvement of sustainable learning among international students.

Finally, sustainable learning is related to sustainable development, which aims to improve the students' knowledge and skills to meet their future goals [87]. That is, sustainable learning refers to the ability of the students to acquire life-long learning so that they can actively participate in the development of their societies $[87,88]$. In this context, international students in HIEs need to adapt to some challenges so that they can foster their life-long learning and improve their skills and knowledge. Accordingly, overcoming language, academic, and research barriers helps international students to get a quality education and to achieve sustainable learning [56,89].

This study aimed to investigate the relation between intercultural learning challenges and sustainable learning among international students in Malaysian HEIs. Sustainable learning in the context of this study involved learning outcomes, which were measured through intercultural language challenges, intercultural academic challenges, intercultural research challenges, and intercultural adaptation to the host culture. The findings showed that language, academic, and research challenges have a negative effect on learning sustainability, especially when these three constructs are related to students' life-long learning skills. However, the study showed no significant relation between intercultural challenges and the learning sustainability construct, which might be attributed to the huge number of international students that allows them to form small communities to overcome adaptation challenges. Also, the multi-cultural, multi-ethnic, and multi-religious aspects of Malaysia made it easier for international students to adapt to the Malaysian culture during their study in Malaysian HEIs. This study concludes that improving international students' learning sustainability has intricate factors related to students, HEIs, lecturers, and educational systems. These factors require a clear framework from HEIs so that international students can gain the expected knowledge, and academic and research skills so that they will be able serve their communities upon the completion of their higher education studies.

One of the implications is that internationalization of education has become a main trend in the globalization of education; however, managing cultural diversity is not an easy task. In the current study, the findings showed that there are not serious intercultural challenges among international students. That is, there were 43 participants in this study from Indonesia, 4 participants from India, 2 participants from China, and 1 participant from Singapore. These countries are known for having a close culture to Malaysian culture, especially Indonesia and Singapore, where people can speak the Malay language. The researchers tried to remove these participants to test if the intercultural challenges hypothesis will be changed from negative to positive; nevertheless, the result of the analysis remained insignificant. This shows that international students face the same intercultural learning challenges in the host country even if their homeland and host country share some cultural and lingual aspects. This also interrelated with the importance of mastering the English language, because English is the medium of instruction in most programs in Malaysian HEIs.

Another implication is that intercultural learning barriers are actually intercultural learning challenges, which the students can overcome with practice. Such intercultural challenges, namely language, academic, and research challenges, are important to improve international students' knowledge and skills, and this educational gaining is considered to be a life-long learning, which is directly related to acquiring sustainable learning.

Besides, improving sustainable learning among international students requires cooperation among lecturers, universities (through labs and facilities), and international students. The cooperation among these learning factors helps to provide life-long learning to international students. 
Another implication is that looking at all the constructs of the study, namely sustainable learning, intercultural challenges, English language challenges, academic challenges, and research challenges, the common factor is English language. Therefore, improving usage of the English language helps to adapt to the host culture, and improve academic gaining and research skills, which makes the English language proficiency the main drive factor to improving learning sustainability in HEIs.

Although our study has contributed to the body of knowledge theoretically and practically in many ways, our study does have limitations. Similar to SEM-PLS small sample size studies, possible bias to the results may occur from individual views. This can be addressed if the sample size in the full-scale study is larger than what we have used in our study based on Krejcie and Morgan's [66] rule thumb.

Based on the findings of the current study, future studies might conduct a comprehensive investigation of the role of intercultural English language challenges in order to test its relation with the outcomes of the students, which is related to learning sustainability among international students. Moreover, future studies might also investigate intercultural learning challenges among international students in relation to gaining sustainable learning. Future studies on this construct could provide a clear picture of its effect on international students, especially by comparing the findings of such future studies with those of the current study.

Furthermore, technology advancements and industry 4.0 innovations such as augmented reality, big data, internet of things, and cloud computing play an essential role in learning and teaching at HEIs [90-93]. Researchers are required to be ahead of these technology advancements at all times by anticipating future developments [94]. Therefore, future research on how technology could sustain learning and teaching process at HEIs is recommended.

Author Contributions: Conceptualization, A.A.Y. and N.A.R.; methodology, A.A.Y.; software, A.A.Y. and Y.A.M.Q.; validation, A.A.Y., N.A.R. and M.A.S.M.; formal analysis, Y.A.M.Q.; investigation, A.A.Y., N.A.R., Y.A.M.Q. and M.A.S.M.; resources, A.A.Y., N.A.R., M.A.S.M. and Y.A.M.Q.; data curation, A.A.Y. and Y.A.M.Q.; writing-original draft preparation, A.A.Y.; writing-review and editing, N.A.R.; and M.A.S.M. supervision, N.A.R.; project administration, N.A.R. All authors have read and agreed to the published version of the manuscript.

Funding: This research and APC was funded by project [Empowering B40 Through 4IR Technology Applications], Faculty of Social Sciences and Humanities, Universiti Kebangsaan Malaysia, grant number [DCP 2017-016/2].

Conflicts of Interest: The authors declare no conflict of interest.

\section{References}

1. Mustafa, J.; Sulehan, J.; Pawanteh, L.; Abdullah, S.; Basri, H.; Muchtar, A.; Mastor, K.A.; Abd Ghani, Z.; Axel, H. Internationalisation and its implications for intercultural maturity among academic staff: A case study. Procedia-Soc. Behav. Sci. 2011, 18, 575-584. [CrossRef]

2. Basow, S.A.; Gaugler, T. Predicting adjustment of US college students studying abroad: Beyond the multicultural personality. Int. J. Intercult. Relat. 2017, 56, 39-51. [CrossRef]

3. Jackson, J. Language, Identity and Study Abroad: Sociocultural Perspectives; Equinox Publishing Ltd.: London, UK, 2008.

4. Holmes, P.; Bavieri, L.; Ganassin, S. Developing intercultural understanding for study abroad: Students' and teachers' perspectives on pre-departure intercultural learning. Intercult. Educ. 2015, 26, 16-30. [CrossRef]

5. Kim, Y.Y. Becoming Intercultural: An Integrative Theory of Communication and Cross-Cultural Adaptation; Sage Publications: Thousand Oaks, CA, USA, 2000. [CrossRef]

6. Al-Zubaidi, K.O.; Rechards, C. Arab Postgraduate Students in Malaysia: Identifying and overcoming the cultural and language barriers. Arab World Eng. J. 2010, 1. [CrossRef]

7. Rovio-Johansson, A. Students' Knowledge Progression: Sustainable Learning in Higher Education. Int. J. Teach. Learn. High. Educ. 2016, 28, 427-439.

8. Lasonen, J. Intercultural Education: Promoting Sustainability in Education and Training. In Work, Learning and Sustainable Development; Springer: Dordrecht, The Netherlands, 2009; pp. 187-202.

9. Smith, R.A.; Khawaja, N.G. A review of the acculturation experiences of international students. Int. J. Intercult. Relat. 2011, 35, 699-713. [CrossRef] 
10. Ahmad, A.L.; Ali, S.; Salman, A.; Salleh, S.M. Intercultural adaptation of nigerian students in malaysia. J. Komun. -Malays. J. Commun. 2016, 32, 105-120.

11. Cheng, H.F.; Yang, M.H.; Chen, K.Y.; Chen, H.L. Measuring perceived EC ethics using a transaction-process-based approach: Scale development and validation. Electron. Commer. Res. Appl. 2014, 13, 1-12. [CrossRef]

12. Shafaei, A.; Razak, N.A. International postgraduate students' cross-cultural adaptation in Malaysia: Antecedents and outcomes. Res. High. Educ. 2016, 57, 739-767. [CrossRef]

13. Strydom, K.; Fourie, C. The perceived influence of diversity factors on effective strategy implementation in a higher education institution. Heliyon 2018, 4, e00604. [CrossRef]

14. Mustapha, S.M.; Rahman, N.S.N.A.; Yunus, M.M. Perceptions towards classroom participation: A case study of Malaysian undergraduate students. Procedia-Soc. Behav. Sci. 2010, 7, 113-121. [CrossRef]

15. Alavi, M.; Mansor, S.M.S. Categories of problems among international students in Universiti Teknologi Malaysia. Procedia-Soc. Behav. Sci. 2011, 30, 1581-1587. [CrossRef]

16. Bin Basri, B.T.R. Multicultural benefits and challenges for international students during period of their study: Case study in Malaysia. J. Educ. Health Commun. Psychol. 2015, 4, 41-54.

17. Busse, V.; Krause, U.-M. Addressing cultural diversity: Effects of a problem-based intercultural learning unit. Learn. Environ. Res. 2015, 18, 425-452. [CrossRef]

18. Sorkos, G.; Hajisoteriou, C. Sustainable intercultural and inclusive education: Teachers' efforts on promoting a combining paradigm. Pedagog. Cult. Soc. 2020, 1-20. [CrossRef]

19. Yang, J.W.M.; Maresova, P. Sustainable Development at Higher Education in China: A Comparative Study of Students' Perception in Public and Private Universities. Sustainability 2020, 12, 2158.

20. Vykydal, D.; Folta, M.; Nenadál, J. A study of quality assessment in higher education within the context of sustainable development: A case study from Czech Republic. Sustainability 2020, 12, 4769. [CrossRef]

21. Pardo-Garcia, C.; Barac, M. Promoting employability in higher education: A case study on boosting entrepreneurship Skills. Sustainability 2020, 12, 4004. [CrossRef]

22. Orozco-Messana, J.; de la Poza-Plaza, E.; Calabuig-Moreno, R. Experiences in transdisciplinary education for the sustainable development of the built environment, the ISAlab workshop. Sustainability 2020, 12, 1143. [CrossRef]

23. Orozco-Messana, J.; Martínez-Rubio, J.M.; Gonzálvez-Pons, A.M. Sustainable Higher Education Development through Technology Enhanced Learning. Sustainability 2020, 12, 3600. [CrossRef]

24. Bennett, M.J. Basic Concepts of Intercultural Communication: Selected Readings; Intercultural Press, Inc.: Yarmouth, ME, USA, 1998.

25. Gudykunst, W.B. Cross-Cultural and Intercultural Communication; Sage: Thousand Oaks, CA, USA, 2003.

26. Rubtsova, A. Socio-Linguistic innovations in education: Productive implementation of intercultural communication. In IOP Conference Series: Materials Science and Engineering; IOP Publishing: Bristol, UK, 2019. [CrossRef]

27. Ramsay, S.; Barker, M.; Jones, E. Academic Adjustment and Learning Processes: A comparison of international and local students in first-year university. High. Educ. Res. Dev. 1999, 18, 129-144. [CrossRef]

28. Robertson, M.; Line, M.; Jones, S.; Thomas, S. International students, learning environments and perceptions: A case study using the Delphi technique. High. Educ. Res. Dev. 2000, 19, 89-102. [CrossRef]

29. Bista, K.; Gaulee, U. Recurring themes across fractal issues facing international students: A thematic analysis of 2016 dissertations and theses. J. Int. Stud. 2017, 7, 1135-1151.

30. Razak, N.A.; Yassin, A.A.; Moqbel, M.S.S. Investigating foreign language reading anxiety among yemeni international students in Malaysian Universities. Int. J. Eng. Linguist. 2019, 9. [CrossRef]

31. Henderson, S.; Barker, M.; Mak, A. Strategies used by nurses, academics and students to overcome intercultural communication challenges. Nurse Educ. Pract. 2016, 16, 71-78. [CrossRef] [PubMed]

32. Jhaiyanuntana, A.; Nomnian, S. Intercultural Communication Challenges and Strategies for the Thai Undergraduate Hotel Interns. PASAA J. Lang. Teach. Learn. Thail. 2020, 59, 204-235.

33. Long, J.H.; Yan, W.H.; Yang, H.D.; Van Oudenhoven, J.P. Cross-cultural adaptation of Chinese students in the Netherlands. US-China Educ. Rev. 2009, 6, 1-9.

34. Hudson, P.; Hudson, S. An Evaluation of an English Language Immersion Programme for ESL Preservice Teachers. Available online: https://eprints.qut.edu.au/19437/1/19437_-_An_evaluation_of_an_English_ language_immersion_programme.pdf (accessed on 12 July 2020). 
35. Farashaiyan, A.; Hua, T.K. A cross-cultural comparative study of gratitude strategies between Iranian and Malaysian postgraduate students. Asian Soc. Sci. 2012, 8, 139. [CrossRef]

36. Tannen, D. The pragmatics of cross-cultural communication. Appl. Linguist. 1984, 5, 189-195. [CrossRef]

37. Biasutti, M.; Concina, E.; Frate, S. Working in the classroom with migrant and refugee students: The practices and needs of Italian primary and middle school teachers. Pedagog. Cult. Soc. 2020, 28, 113-129. [CrossRef]

38. Lou, N.M.; Noels, K.A. Breaking the vicious cycle of language anxiety: Growth language mindsets improve lower-competence ESL students' intercultural interactions. Contemp. Educ. Psychol. 2020, 61, 101847. [CrossRef]

39. Mehdizadeh, N.; Scott, G. Adjustment problems of Iranian international students in Scotland. Int. Educ. J. 2005, 6, 484-493.

40. Sun, W.; Chen, G.-M. Dimensions of Difficulties Mainland Chinese Students Encounter in the United States. In Proceedings of the 6th International Conference on CrossCultural Communication, Tempe, AZ, USA, 27 March 1997.

41. Andrade, M.S. International students in English-speaking universities: Adjustment factors. J. Res. Int. Educ. 2006, 5, 131-154. [CrossRef]

42. Wang, S.; Moskal, M.; Schweisfurth, M. The social practice of silence in intercultural classrooms at a UK university. Comp. J. Comp. Int. Educ. 2020, 1-18. [CrossRef]

43. Tualaulelei, E. Professional development for intercultural education: Learning on the run. Asia-Pac. J. Teach. Educ. 2020, 1-14. [CrossRef]

44. Li, M.; Campbell, J. Cultural Adaptation: A Case Study of Asian Students' Learning Experiences at a New Zealand University. 2006. Available online: https://ro.ecu.edu.au/ceducom/86 (accessed on 27 August 2020).

45. Nasir, M. Effects of cultural adjustment on academic achievement of international students. J. Elem. Educ. 2012, 22, 95-103.

46. Komarraju, M.; Nadler, D. Self-efficacy and academic achievement: Why do implicit beliefs, goals, and effort regulation matter? Learn. Individ. Differ. 2013, 25, 67-72. [CrossRef]

47. Khan, A.; Hamdan, A.R.; Ahmad, R.; Mustaffa, M.S. International student's academic achievement: Contribution of gender, self-efficacy and socio-cultural adjustment. Asian Soc. Sci. 2015, 11, 153. [CrossRef]

48. Alt, D. Constructivist learning and openness to diversity and challenge in higher education environments. Learn. Environ. Res. 2017, 20, 99-119. [CrossRef]

49. Donald, J.G.; Denison, D.B. Evaluating undergraduate education: The use of broad indicators. Assess. Eval. High. Educ. 1996, 21, 23-39. [CrossRef]

50. Lin, L.; Huang, Z.; Othman, B.; Luo, Y. Let's make it better: An updated model interpreting international student satisfaction in China based on PLS-SEM approach. PLoS ONE 2020, 15, e0233546. [CrossRef] [PubMed]

51. Lu, W.; Mundorf, N.; Ye, Y.; Lei, W.; Shimoda, K. The Impact of Class Discussions on Attitudes of Chinese Students in the US towards Culture and Sustainability. China Media Res. 2015, 11, 110-118.

52. Samuelsson, I.P.; Park, E. How to educate children for sustainable learning and for a sustainable world. Int. J. Early Child. 2017, 49, 273-285. [CrossRef]

53. Jakobsson, A.; Davidsson, E.; Karlsson, K.G.; Oskarsson, M. Exploring epistemological trends in students' understanding of science from the perspective of large-scale studies. ISRN Educ. 2013, 2013, 196014. [CrossRef]

54. Bowden, J.A.; Marton, F. The University of Learning; Psychology Press: Gothenburg, Sweden, 1998; ISBN 0-7494-2292-0.

55. Hatipoglu, B.; Ertuna, B.; Sasidharan, V. A referential methodology for education on sustainable tourism development. Sustainability 2014, 6, 5029-5048. [CrossRef]

56. Tilbury, D. Higher education for sustainability: A global overview of commitment and progress. High. Educ. World 2011, 4, 18-28.

57. Saadatian, O.; Salleh, E.; Tahir, O.; Dola, K. Observations of sustainability practices in Malaysian research universities: Highlighting particular strengths. Pertanika J. Soc. Sci. Humanit. 2009, 17, 225-244.

58. Sekaran, U.; Bougie, R. Research Methods for Business, a Skill Building Approach; John Willey \& Sons Inc.: New York, NY, USA, 2003.

59. Gill, S. Overseas students' intercultural adaptation as intercultural learning: A transformative framework. Compare 2007, 37, 167-183. [CrossRef] 
60. Trice, A.G. Faculty perceptions of graduate international students: The benefits and challenges. J. Stud. Int. Educ. 2003, 7, 379-403. [CrossRef]

61. Elliot, D.L.; Reid, K.; Baumfield, V. Beyond the amusement, puzzlement and challenges: An enquiry into international students' academic acculturation. Stud. High. Educ. 2016, 41, 2198-2217. [CrossRef]

62. Hellstén, M. International student transition: Focusing on researching international pedagogy for educational sustainability. Int. Educ. J. Comp. Perspect. 2013, 8, 79-90.

63. Fadeeva, Z.; Mochizuki, Y.; Brundiers, K.; Wiek, A.; Redman, C.L. Real-world learning opportunities in sustainability: From classroom into the real world. Int. J. Sustain. High. Educ. 2010. [CrossRef]

64. Gelo, O.; Braakmann, D.; Benetka, G. Quantitative and qualitative research: Beyond the debate. Integr. Psychol. Behav. Sci. 2008, 42, 266-290. [CrossRef] [PubMed]

65. Cresswell, J. Qualitative Inquiry E Research Design: Choosing between Five Methods; SAGE Publishing, Inc.: Thousand Oaks, CA, USA, 2012.

66. Krejcie, R.V.; Morgan, D.W.J.E.; Measurement, P. Determining sample size for research activities. Educ. Psychol. Meas. 1970, 30, 607-610. [CrossRef]

67. Roscoe, J.T. Fundamental Research Statistics for the Behavioral Sciences; Rinehart and Winston: New York, NY, USA, 1975. [CrossRef]

68. Barclay, D.; Higgins, C.; Thompson, R. The partial least squares (PLS) approach to casual modeling: Personal computer adoption ans use as an Illustration. Technol. Stud. 1995, 2, 285-309.

69. O'Rourke, N.; Hatcher, L. A Step-by-Step Approach to Using SAS for Factor Analysis and Structural Equation Modeling; Sas Institute: Cart, NC, USA, 2013; ISBN 1629592447.

70. Hair, J.F.; Hult, G.T.M.; Ringle, C.; Sarstedt, M. A Primer on Partial Least Squares Structural Equation Modeling (PLS-SEM); Sage Publications: Thousand Oaks, CA, USA, 2016.

71. Faul, F.; Erdfelder, E.; Buchner, A.; Lang, A.G. Statistical power analyses using G* Power 3.1: Tests for correlation and regression analyses. Behav. Res. Methods 2009, 41, 1149-1160. [CrossRef]

72. Vidaver-Cohen, D. Moral climate in business firms: A conceptual framework for analysis and change. J. Bus. Ethics 1998, 17, 1211-1226. [CrossRef]

73. Hongmei, P. The Cross-Cultural Adaptation of Chinese Students in the US. 2017. Available online: http://www.celea.org.cn/pastversion/lw/pdf/panghongmei.pdf (accessed on 25 August 2020).

74. Hair, J.F.; Ringle, C.M.; Sarstedt, M. PLS-SEM: Indeed a silver bullet. J. Mark. Theory Pract. 2011, 19, $139-152$. [CrossRef]

75. Chin, W.W. How to write up and report PLS analyses. In Handbook of Partial Least Squares; Springer: Heidelberg, Germany, 2010; pp. 655-690.

76. Hair, J.F.; Black, W.C.; Babin, B.J.; Anderson, R.E. Multivariate Data Analysis; Prentice Hall: Upper Saddle River, NJ, USA, 1998; Volume 5.

77. Ramayah, T.; Cheah, J.; Chuah, F.; Ting, H.; Memon, M.A. Partial Least Squares Structural Equation Modeling (PLS-SEM) Using Smartpls 3.0, in an Updated Guide and Practical Guide to Statistical Analysis; Pearson: Kuala Lampur, Malaysia, 2018.

78. Qasem, Y.A.M.; Asadi, S.; Abdullah, R.; Yah, Y.; Atan, R.; Al-Sharafi, M.A.; Yassin, A.A. A Multi-Analytical Approach to predict the determinants of cloud computing adoption in higher education institutions. Appl. Sci. 2020, 10, 4905. [CrossRef]

79. Fornell, C.; Larcker, D.F. Evaluating structural equation models with unobservable variables and measurement error. J. Mark. Res. 1981, 18, 39-50. [CrossRef]

80. Podsakoff, P.M.; MacKenzie, S.B.; Lee, J.Y.; Podsakoff, N.P. Common method biases in behavioral research: A critical review of the literature and recommended remedies. J. Appl. Psychol. 2003, 88, 879-903. [CrossRef] [PubMed]

81. Yusoff, Y.M.; Chelliah, S. Adjustment in international students in Malaysian public university. Int. J. Innov. Manag. Technol. 2010, 1, 275.

82. McMillin, J.; Dyball, R. Developing a whole-of-university approach to educating for sustainability: Linking curriculum, research and sustainable campus operations. J. Educ. Sustain. Dev. 2009, 3, 55-64. [CrossRef]

83. Peris-Ortiz, M.; Lindahl, J.M.M. Sustainable Learning in Higher Education; Springer: Berlin/Heidelberg, Germany, 2015. [CrossRef] 
84. Razak, N.A.; Yassin, A.A.; Maasum, T.N.R.T.M. Formalizing Informal CALL in Learning English Language Skills, in Enhancements and Limitations to ICT-Based Informal Language Learning: Emerging Research and Opportunities. IGI Global. 2020. [CrossRef]

85. Kahl, C. A deeper lecturer and student view of a sustainable learning requirement in tertiary education in Malaysia. Int. J. Cross-Discip. Subj. Educ. 2013, 4, 1144-1152. [CrossRef]

86. Ahmad, A.L.; Azimi, H.; Salleh, S.; Mohamad, E.M.; Sannusi, S.N. The intercultural adaptation experience of Afghan students in Malaysia. In SHS Web of Conferences; EDP Sciences: Kuala Lumpur, Malaysia, 2017. [CrossRef]

87. Boud, D. Sustainable assessment: Rethinking assessment for the learning society. Stud. Contin. Educ. 2000, 22, 151-167. [CrossRef]

88. Sidiropoulos, E. Education for sustainability in business education programs: A question of value. J. Clean. Prod. 2014, 85, 472-487. [CrossRef]

89. Adomssent, M.; Godemann, J.; Michelsen, G.; Barth, M.; Rieckmann, M.; Stoltenberg, U. Developing key competencies for sustainable development in higher education. Int. J. Sustain. High. Educ. 2007. [CrossRef]

90. Qasem, Y.A.; Abdullah, R.; Atan, R.; Jusoh, Y.Y. Cloud-Based Education As a Service (CEAAS) System Requirements Specification Model of Higher Education Institutions in Industrial Revolution 4.0. Int. J. Recent Technol. Eng. (IJRTE) 2019, 8. [CrossRef]

91. Qasem, Y.A.M.; Rusli, A.; Yusmadi, J.; Rodziah, A.; Mohammed, A.A.-S.; Mostafa, A.-E. Towards the Development of a Comprehensive Theoretical Model for Examining the Cloud Computing Adoption at the Organizational Level, in Recent Advances in Intelligent Systems and Smart Applications; Springer: Berlin/Heidelberg, Germany, 2020; pp. 63-74. [CrossRef]

92. Qasem, Y.A.M.; Rusli, A.; Rodziah, A.; Yusmadi, Y.J. Mapping and Analyzing Process of Cloud-based Education as a Service (CEaaS) Model for Cloud Computing Adoption in Higher Education Institutions. In Proceedings of the 2018 Fourth International Conference on Information Retrieval and Knowledge Management (CAMP), Kota Kinabalu, Malaysia, 26-28 March 2018; IEEE: Piscataway, NJ, USA, 2018. [CrossRef]

93. Qasem, Y.A.; Abdullah, R.; Jusoh, Y.Y.; Atan, R. Conceptualizing a model for Continuance Use of Cloud Computing in Higher Education Institutions. In Proceedings of the AMCIS 2020 TREOs, Salt Lake City, UT, USA, 10-14 August 2020.

94. Qasem, Y.A.; Abdullah, R.; Jusoh, Y.Y.; Atan, R.; Asadi, S. Cloud computing adoption in higher education institutions: A systematic review. IEEE Access 2019, 7, 63722-63744. [CrossRef] 